\title{
Aspectos estratégicos da marca para a construção da imagem empresarial
}

\author{
Strategic aspects in the brand design for \\ the enhancement of the corporate identity
}

por Benedetta Terenzi

RESUMO

tradução de Milton de Andrade

Este artigo nasce como ulterior aprofundamento e reflexão sobre temas relativos ao design gráfico e às suas diversas formas de expressão e declinação, com o desejo de colocar maior atenção nas problemáticas concernentes ao projeto em duas dimensões. Ludibriados pela cultura superficial das mídias (que, todavia, "fazem opinião), quem se aproxima desta disciplina, seja aquele que frequenta um curso de estudos específicos ou um autodidata, frequentemente ignora ou confunde o significado semântico e cultural de alguns termos específicos usados no setor. 0 objetivo didático deste texto é, portanto, ilustrar alguns aspectos propedêuticos e estratégicos inerentes ao projeto de design gráfico. Partindo do esclarecimento dos conceitos de caráter geral, foram abordados vários âmbitos do setor disciplinar, com foco sobre problemáticas peculiares de cada um destes. A análise realizada permitiu a delineação da estrutura geral do âmbito da intervenção, os componentes fundamentais e as modalidades de relação entre essas, permitindo identificar quais devam ser as regras conceituais por meios das quais organizar um artefato comunicativo. Confirma-se assim, de forma clara, o pertencimento do design gráfico e do design visual à mais vasta e articulada área da cultura do projeto.

Palavras-chave imagem; projeto; marca; comunicação gráfica; embalagem

ABSTRACT

This essay began as a further discussion and reflection on issues related to graphic design and its different forms of expression and declination, with a willingness to pay more attention to problems relating to the project in two dimensions. Misled by careless culture media (who, "they say"), who comes to this discipline, or attending a specific course of study or is a self-taught, often ignores or confuses the semantic meaning and cultural specific terms used in the field. The educational objective of this paper is therefore to illustrate some aspects, preparatory and strategic concerning the project of graphic design. Based on the clarification of the concepts of a general nature, we have covered the various areas of the field of study focusing on the specific problems of each. The analysis carried out has allowed us to define the overall structure of the study area, the basic components and the methods of interaction between them allowing to identify the conceptual rules by which organize an artifact of visual communication. It validates so fully the relevance of graphic and visual design to the most extensive and varied area of design culture.

Keywords corporate image; visual design; brand name; graphic communication; packaging 
Ao introduzir um tema complexo e articulado como o da comunicação gráfica, antes de tudo, gostaríamos de destacar um aspecto de interesse especial que caracteriza 0 design visual, e representa o trait-ďunion entre dois setores contrapostos: a pintura, entendida como "arte pura" bidimensional, e o design, entendido no sentido estrito do termo e, portanto, reiterável e referido a uma projetação destinada sobretudo a objetivos utilitários. De um lado, de fato, a projetação gráfica expressa algumas características expressivas que costumeiramente se atribui ao setor das artes visuais e, por outro, se baseia em conceitos projetuais típicos do projeto de design que vai do product design ao packaging, incluindo a arquitetura. "0 Universo do design visual se estende da 'ilustração' ao cartaz publicitário, da fotografia expressamente programada ao lettering, da sinalização das estradas até aquilo que é o verdadeiro "ápice projetual" desta disciplina: a imagem coordenada que é a primeira pedra com a qual se constrói a grande muralha da comunicação visual relativa à indústria, a uma companhia, a uma empresa, mas também a uma imagem cívica, política, esportiva, e até mesmo nacional." (DORFLES, 1984, p. 11, trad. nossa).

Justamente pela vastidão do seu campo de expressão, a projetação gráfica desempenha um papel importante não somente de um ponto de vista estético, mas também do ponto de vista da "dignidade nacional", da homogeneidade social e da educação do gosto do público. "Tenho afirmado várias vezes que uma boa arte gráfica difundida traz mais vantagens para a educação do gosto visivo de uma inteira população do que possa fazer muitas salas de museus e muitas mostras mais ou menos de vanguarda. Até mesmo por uma simples razão: a relação entre arte gráfica e artes visuais 'puras' é tão íntima que frequentemente é difícil discernir se foi a pintura ou a arte gráfica que primeiro inventou uma nova linguagem visiva". (DORFLES, in ILIPRANDI (et al), 1984, p. 13).

Fazendo um pequeno passo atrás, é útil sem dúvida deter-se na definição terminológica do âmbito a que nos referimos, retomando o pensamento de alguns operadores emblemáticos. Todos aqueles que operam neste setor, de fato, dos projetistas aos críticos, expressaram uma definição do termo. Segundo Giovanni Anceschi, o termo "arte gráfica", da locução ars graphica (técnica do escrever) "tende a coincidir com aquele da locução anglo-saxã 'visual' ou graphic design".'

Gillo Dorfles aponta para uma "projetação global voltada a um determinado produto, objeto, operação, e não somente a um singular sinal privo daquelas características programadoras e de estruturação global e unitária próprias do design" (DORFLES, 1972, p. 43). 0 autor considera também que o termo inglês visual design é aquele que consegue, melhor que todos, envolver no seu significado "todas as atividades projetivas voltadas à arte gráfica, tipografia, lettering, fotografia, cinematógrafo, desenhos animados" (DORFLES, 1972, p. 122). Anty Pansera concretiza estes conceitos

1 Cf. item "arte gráfica" da Enciclopedia Europea Garzanti. 
com a expressão "comunicação visual industrial" ', termo que nos parece adequado para compreender de modo coerente o conjunto das afirmações apresentadas.

Atualmente a comunicação visual nos invade e nos penetra todos os dias, a cada momento, nas formas mais variadas, procurando tomar nossa atenção: parece nos urrar de modo imponente ou nos sussurrar afavelmente uma quantidade desmedida de informações. Por isso, querendo colocar-se diante de possíveis desenvolvimentos projetuais, entendemos que se deva constatar como o componente de "poluição semântica" possa estar presente seja na falta da qualidade dos conteúdos como na abundância comunicativa, como nos sugere Tòmas Maldonado que destaca quanto "o aborrecimento - 'a nostalgia do conteúdo' como a define Marx - está presente tanto na imobilidade da escassez de imagens quanto no tumulto da sua superabundância [...]" e prossegue, referindo-se a Las Vegas, "[...] cada sign aqui é uma mensagem estereotipada, um veículo semântico cristalizado cuja aderência ao que pretende designar, denotar ou significar não é jamais colocada em causa. 0 que resulta é uma comunicação epidérmica, priva de densidade e consistência: em síntese, uma comunicação fictícia, um simulacro de comunicação, somente falatório, somente rumor". (MALDONAD0, 1970, p. 121, trad. nossa).

Quando se quer explicar as metodologias do projeto de comunicação visual, não se pode eximir de esclarecer sobre qual seria o objeto entorno do qual se constrói o processo comunicativo. Neste ponto, entra em jogo um esclarecimento verbal fundamental, isto é, a diferença de significado entre o conceito de identidade e de imagem. No linguajar comum, estas duas palavras podem significar a mesma coisa ou coisas muito parecidas e até, às vezes, uma é usada indiferentemente no lugar da outra. Na realidade, elas exprimem dois conceitos muito diferentes; apesar de ser correto afirmar que tanto a identidade como a imagem aludem à comunicação de mensagens, elas o fazem, porém, com objetivos totalmente diferentes.

No caso de uma pessoa, por exemplo, a identidade serve para identificá-la de modo unívoco por meio de características principais como o nome, o sobrenome, a altura, a cor dos cabelos, a cor dos olhos, os sinais individuais, etc. Cada pessoa tem no momento em que nasce sua identidade que depois, mais ou menos rapidamente, evolui no tempo; todavia, apesar da mudança fisiológica, cada indivíduo continua a reconhecer-se nela. Por isso, cada um de nós, quando se levanta de manhã e se olha no espelho, partindo da objetividade da sua identidade, elabora um específico projeto próprio de imagem pessoal. Com base nas diversas circunstâncias que caracterizam o desenrolar daquele dia específico (como os compromissos de trabalho, os sociais e mesmo os fatores mais subjetivos como o humor, etc.), cada pessoa programa sua própria imagem: na base de uma série de reflexões, ela decidirá usar esta ou aquela peça do vestuário, aqueles sapatos porque são mais cômodos ou outros porque são

2 Vide Anty Pansera, La storia di un percorso, in G. Iliprandi, A. Marangoni, F. Origoni e A. Pansera "Visual Design; cinquant'anni di produzione in Italia", Milano: Idealibri, 1984, p. 15. 
elegantes; no caso de uma mulher, uma maquiagem acqua e sapone ou um belo batom vermelho, etc. A partir deste ponto, a sua identidade se torna o resultado do projeto de "como se quer parecer" naquele momento, naquela determinada circunstância: a chamada "imagem". A imagem é, portanto, o resultado de uma escolha que incide sobre a natureza objetiva das coisas. Em conclusão, podemos afirmar que a construção da imagem é um ato consciente e, como tal, é também fruto de uma elaboração racional. Demos então resposta à questão: a formulação da imagem é o objeto do projeto de comunicação.

Saindo da simplificação para se tornar à especificidade do caso, devemos sublinhar como, e em que modo, as realidades operativas podem usufruir utilmente de um bom projeto de imagem gráfica já que este, no caso de instituições, empresas ou entidades de vários tipos, não tem somente um valor formal mas inclui uma validade operativa rica de conteúdos. Trata-se do projeto de arte gráfica que definimos "institucional", pois se ocupa das comunicações daquelas mensagens que duram no tempo e têm um caráter sistemático. Referimo-nos, sobretudo, aos fenômenos gráficos que permitem capitalizar positivamente na marca todas as ações perceptíveis de uma entidade: os vários elementos da arte gráfica institucional são concebidos e declinados sob diversões aspectos pelos quais as empresas devem fazer convergir todas as suas energias de comunicação. ${ }^{3}$

Diferentemente do projetista publicitário, que raciocina para campanhas "com duração programada" (no sentido que têm um objetivo comercial a se queimar de seis em seis meses), a estratégia de uma imagem institucional raciocina de modo oposto: trabalha sobre tudo o que é necessário para se realizar aquelas mensagens contingentes que servem à empresa ou ao órgão administrativo para se obter reconhecimento e para capitalizar todas as valências positivas expressas no tempo. ${ }^{4}$

Na base da expressão de uma boa imagem está, por sua vez, a marca, que é o instrumento mais sintético do projeto em duas dimensões utilizado para comunicar. Projetar ou renovar a imagem de uma instituição é uma ação muito importante e ao mesmo tempo muito delicada, pois significa tornar consciente e programável o processo de formação dos juízos dos usuários. Neste sentido, a elaboração de uma "imagem coordenada" é aquele programa de ações voltadas a controlar e qualificar todos aqueles "fenômenos" visivos que podem ser percebidos pelos interlocutores. ${ }^{5}$

Mesmo não sendo o único a fazer parte do conceito de "imagem", o aspecto visual é porém aquele considerado mais importante pela imediatez com a qual se mani-

3 Cf. Alessandro Ubertazzi, Manuali Upim, 1967-1969. Un progetto di grafica sistematica, in "Rassegna" n. 6 (Il campo della grafica italiana), C.I.P.I.A., Bologna, aprile 1981, p. 45-47.

4 Cf. Alessandro Ubertazzi, Dalle due alle tre dimensioni, premessa in Dalle due alle tre dimensioni. Riflessioni propedeutiche ...... di Benedetta Terenzi, Edizioni Vallelmagna, luglio 2012, p. 3.

5 Vide Alessandro Ubertazzi (et al), Note per definire il concetto di immagine aziendale coordinata, dispensa del DA, Centro per il Disegno Ambientale, Milano, febbraio 1972. 
festa e se memoriza. Como dissemos, a marca, então, representa a primeira forma de interação entre um usuário e a instituição à qual se refere (qualquer que seja). Uma marca é o termômetro que mede, em termos absolutos e sintéticos, o próprio valor de uma empresa ou de uma instituição, e o identifica no imaginário coletivo.

É significativo recordar como que, na Idade Média, os construtores de catedrais (e especialmente os entalhadores, cuja tarefa era esquadrejar as pedras úteis à edificação) costumavam "assinar" as suas obras com sinais pessoais. Estes sinais eram verdadeiras marcas próprias identificadoras de todos pedreiros (maçons), representando geralmente figuras geométricas construídas de acordo com um esquema e uma estrutura de base.

"Eu vi muitas catedrais: em muitas delas os lapidadores deixaram as suas assinaturas, as suas siglas frequentemente consistindo num elaborado monograma. É evidente que a assinatura nos manufaturados consiste num procedimento prático para identificar o quantitativo de peças inscritiveis a um ou outro trabalhador, mas revela seguramente 0 orgulho pessoal de quem pertence a um nivel superior de trabalhadores do canteiro de obras, isto é àqueles mestres que levaram às construções a qualidade de execução aos niveis máximos que nós conhecemos. [...] Estes pedreiros "assinam" o empenho inexaurivel nos seus excelentes trabalhos desejados por uma coletividade que aspira do mesmo modo à sua legítima qualidade." (UBERTAZZI, 2007, p. 49, trad. nossa)

Até mesmo os próprios brasões, selos, estandartes e bandeiras representaram, e representam até hoje, verdadeiras marcas destinadas a sublinhar o pertencimento das pessoas a grupos de vários tipos aos quais essas desejavam mostrar que faziam parte: Estados, regiões, cidades, famílias, castas, seitas, partidos, etc.

Tudo isto evidencia ulteriormente que, por sua natureza, a marca como instrumento comunicativo e identificativo é uma mensagem sintética que deve ser incisiva e memorizável. Para que isto ocorra de modo correto, ela deve ser projetada e para tal devem ser utilizadas regras exatas e codificadas.

Até aqui falamos genericamente de marca, mas é necessário especificar que uma marca pode ser chamada também "logo" (do grego, logos que significa "palavra"), quando esta se concretiza numa escrita mais ou menos desenhada, que se torna ela própria expressão de uma identidade; neste caso, de todo modo, se falará preferivelmente de "logotipo". Para que um logotipo exista e funcione não é, porém, suficiente uma estreita associação entre signo gráfico e significado da palavra. Um exemplo conhecido e emblemático de logotipo é representado pela escrita "Pirelli": na sua imediata leitura, por um lado, se percebe o nome da indústria (com a sua vocação técnica e a sua dimensão internacional) e, do outro, a mensagem fornecida pelo seu grafismo ( 0 "P" alongado) que evoca imediatamente a característica principal do seu job: a elasticidade dos pneus que produz.

A este propósito é interessante referir-se ao pensamento de Tomàs Maldonado: 
Uma marca é um signo gráfico com função simbólico-emblemática. Ela serve para indicar, no interior de uma classe de objetos, o estatuto particular de uma categoria de seus membros. Muito frequentemente cria fictícias dessemelhanças onde existem reais semelhanças. 0 que tem uma explicação: na nossa atual ordem sócio-econômica, o estatuto que a marca explicita é geralmente relativo aos objetos vistos 'como mercadorias', isto é, como principais protagonistas do sistema de troca. É óbvio que quando os produtores são diferentes e os produtos são mais ou menos os mesmos, como de fato ocorre no sistema de troca contemporâneo, a marca assume uma importância decisiva. Em tal contexto, raramente os objetos têm uma força auto-identificatória suficiente para se poder prescindir da marca. A marca é então, por assim dizer, uma prótese que vem preencher uma insuficiência do objeto como mercadoria. A marca contribui para colocar em evidência o nexo existente entre um objeto e seu proprietário, fabricante ou destinatário. Às vezes também entre um objeto e o seu lugar de origem, de produção ou de destino. (MALDONADO, 1981, p. 34, trad. nossa).

Paul Rand, criador da marca IBM, disse a tal propósito: "uma marca de fábrica é criada por um artista gráfico, mas feita por uma empresa (ou desfeita!)". A este ponto, deve-se evidenciar que tipo de relação se interpõe entre a marca empresarial e a definição da imagem dos seus produtos. É com a presença da marca que se tem a "passagem dos aspectos materiais aos aspectos imateriais do produto" (SEMPRINI, 1993, p. 27). A imagem da marca, o brand image, é "a fisionomia que um produto de marca tem num determinado momento junto ao público de consumidores" (BASSO CRIVELLI, in MUTARELLI, 1981, p. 25). 0 brand name é a tradução de uma marca em linguagem visual, e sobre ele se apoiarão todos os outros elementos que constituem o identikit da empresa, isto é, que compõem a sua imagem coordenada. 0 projeto da imagem coordenada de qualquer instituição ou empresa se exprime por meio de diversos suportes comunicativos que devem possuir uma coerência expressiva evidente que parte, por sua vez, do próprio projeto-marca ${ }^{6}$.

Todos os componentes que colaboram à coordenação da imagem empresarial são perfeitamente classificados no texto do professor Alessandro Ubertazzi Classificazione di componenti per il coordinamento dell'immagine visuale (1972). A título de exemplificação apresento parte da classificação na qual o professor especifica os elementos necessários à imagem gráfica: marca principal, logotipo principal, emblemas para marcas privadas, logotipos para marcas privadas, caracteres tipográficos preferenciais, cores preferenciais, política da cor, normativa dos formatos, normativa para os fluxos de papéis internos, impressos, comunicação técnica, normativa para os fluxos de papéis externos, papel timbrado, papel timbrado das

6 Vide Alessandro Ubertazzi (et al), Classificazione di componenti per il coordinamento dell'immagine aziendale, dispensa del DA, Centro per il Disegno Ambientale, Milano, febbraio 1972. 
marcas privadas, gráfica para os meios de transporte, concepção dos stands e das instalações para feiras, expositores, uniformes. E ainda, para a apresentação do produto industrial são necessários: normativa dos formatos para a embalagem, normativa dos materiais para a embalagem, projeto de confecções-embalagens, instruções de uso (dépliant), papéis de embalagem, catálogos, expositores, etc.

Entre todos os elementos até aqui indicados, no nosso entender é importante se ater naquele especial artefato entre os mais emblemáticos da comunicação de uma empresa: a embalagem dos produtos. Não somente pela crescente importância estratégica que elas representam, mas também pelo grau de presença visual que assumem na nossa vida cotidiana, as embalagens sofreram um desenvolvimento formal e técnico importante transformando-se de simples recipientes a um articulado conjunto de objetos muito heterogêneos aos quais é cada vez mais confiada a função de comunicar e informar.

Com o início da Revolução Industrial e com o consequente abandono do campo se estimulou o crescimento das cidades. Os habitantes das cidades não tinham possibilidade de conservar os produtos como se fazia numa fazenda, por exemplo, e assim a quantidade dos produtos adquiridos tendia a ser reduzida e as visitas às lojas mais frequentes. Esta situação foi uma clara oportunidade para criar as confecções individuais, num formato mais consonante às necessidades dos clientes, colocando assim maior atenção também na apreciação estética do invólucro. Como consequência ocorre que, enquanto que nas pequenas lojas os artesãos vendiam os seus artigos e conseguiam encontrar as várias possibilidades para utilizar melhor um produto, os grandes armazéns eram gerenciados por pessoas com pouquíssimo conhecimento, ou até nenhum, dos produtos e das suas aplicações: o consumidor se encontrava cara a cara com o produto embalado. Deste modo, o papel motivacional e informativo da confecção se torna fundamental: a embalagem devia informar o comprador e devia vender o produto encarregando-se de novas funções que the valeram o apelido de silent salesman, definição que influenciará de modo substancial o desenvolvimento posterior da embalagem. Nesta fase ocorre a passagem de produto a mercadoria e, como ressalta Walter Benjamin, "com a etiqueta do preço, a mercadoria faz o seu ingresso no mercado [...] adquiriu uma 'objetividade espectral' e conduz uma vida própria". (BENJAMIN, 1986, p. 241)

Daquele momento, a marca de identificação é transferida da embalagem em conjunto às confecções individuais ou às etiquetas. Esta foi uma forma inicial de diferenciação dos produtos e também a origem do termo brand name, ou então marca ou nome comercial. Apesar de não podermos fixar historicamente de maneira precisa a passagem da simples embalagem ao packaging, podemos afirmar que este estabelece suas raízes no quadro sócio-econômico dos Estados Unidos dos anos 1930. Naquele momento, de fato, o recipiente era preparado para dar resposta àquelas necessidades de "cisão do produto num corpo do produto ou portador da função, e num invólucro do produto, preparado independentemente daquele, para atrair o comprador por meio do fascínio da aparência e para estimular a compra das mercadorias" (BONSIEPE, 1975, p. 29). 
0 design e a arte gráfica da embalagem se tornaram de repente alguma coisa mais que uma bela imagem: "0 packaging é, de certo modo, a marca da mercadoria, é o meio para imprimir sobre um objeto o signo do seu ser produto industrial; ou seja, é a expressão comunicativa do produto" (BUCCHETTI, 2004, p. 29, trad. nossa).

Hoje o packaging mostra querer evoluir dentro de uma nova cultura do design estratégico para propor-se à indústria como um serviço integrado a longo termo, por este motivo os profissionais que operam no setor tendem a trabalhar em paralelo não somente sobre a imagem de uma confecção individual, mas projetando uma estratégia empresarial: da arte gráfica à arquitetura comercial, à identidade corporativa.

Sabemos, até mesmo parece óbvio, que "poucos objetos são nos dias de hoje oferecidos isoladamente, sem um contexto de outros objetos que os coloque em relevo. E a relação do consumidor com o objeto é assim modificada: ele não se refere mais àquele objeto na sua utilidade específica, mas a um conjunto de objetos no seu significado total. [...] A vitrine, o anúncio publicitário, a companhia produtora e a marca, que aqui exerce um papel essencial, impõem a visão coerente, coletiva, como uma cadeia que não é mais a concatenação de objetos individuais mas uma concatenação de significados, na medida em que esses significam um e outro como um super-objeto mais complexo e atraem o consumidor para uma série de motivações mais complexas." (BAUDRILLARD, 1976, p. 17, trad. nossa).

Por outro lado, o consumidor de hoje não é sequer pan-europeu, mas mundial; e o packaging de um produto permanece a melhor interface para a superação das diferenças de língua e de hábitos. Gui Bonsieppe afirma: “[...] a estetização das mercadorias não tem valor somente para o produtor, na medida em que estimula 0 consumo e desvia a crítica do valor de uso, mas também para o consumidor. Este último, na própria incapacidade de dominar a crescente complexidade técnica dos produtos e de julgar criticamente o valor de uso, substitui o gosto, isto é, a capacidade de diferenciação estética." (BONSIEPE, 1975, p. 29, trad. nossa).

Esta afirmação nos oferece a possibilidade de fechar o círculo entorno da problemática do projeto de comunicação visual industrial. Efetivamente, numa civilização como a nossa (que, justamente, pode ser chamada "da comunicação") os ingredientes que constituem a imagem oficial de qualquer instituição bem gerida permanecem habitualmente impressos na memória do público e, portanto, podem se carregar de tantos significados para assumir um explícito valor comercial. Certas marcas são assim fortemente enraizadas no imaginário coletivo de modo que sobrevivem além da produção dos bens e dos serviços para os quais elas foram originalmente concebidas e utilizadas.

Se é verdade, como em geral ensinamos aos nossos estudantes que frequentam os nossos cursos, que o design é um tipo especial de projeto e, como tal, é um verdadeiro e próprio pensamento que ocorre para dar resposta a uma necessidade humana e que, mais especificamente, o projeto de design refere-se tout-court ao projeto das coisas que constituem a bagagem cotidiana do ser humano de modo correspondente à lógica das máquinas, à índole dos materiais utilizados, à cultura 
formal do próprio tempo e evidenciando uma explícita dimensão ética e social ?, podemos concluir que este excursus na disciplina, nas várias declinações abordadas, nos permitiu demonstrar como, por suas características processuais e pela inequívoca necessidade de corresponder com um pensamento rigoroso a uma necessidade, que no nosso caso se trata de exigências profissionais de uma imagem eficaz, a projetualidade e as metodologias da arte gráfica institucional são reconduzíveis substancialmente àquelas do design industrial. De fato, analogamente a todos os outros setores do design, a projetualidade da arte gráfica institucional deve corresponder também de modo atualizado às lógicas reprodutivas (por exemplo, aos procedimentos tipográficos mais avançados), deve interpretar a índole dos materiais que utiliza (os infinitos tipos de papéis e de outros suportes), deve exprimir-se de acordo com os costumes estéticos (isto é, expressivos e formais) do seu tempo e, sobretudo, daqueles por vir e, enfim, não pode prescindir de uma consciente coerência ética8. Um artefato arquitetônico, um plano diretor, o desenho de uma poltrona, a cenografia de uma obra teatral, um roteiro cinematográfico, uma partitura musical ou uma marca, no fundo, são todos contemporaneamente signos e estruturas de signos, são todos o resultado de uma exigência de comunicação, de um pensamento e, então, de um projeto.

7 Vide Benedetta Terenzi, Progetto e design nel settore dell'occhialeria, in "l'0ttico", Diffusione Scientifica S.r.l., Sesto Fiorentino, maggio-agosto 2011, p. 9-12.

8 Cf. Alessandro Ubertazzi, premessa in Benedetta Terenzi, II progetto a due dimensioni. Riflessioni propedeutiche al design grafico con esperienze didattiche, edizioni Valle Imagna, Stampa Grafica Monti, Bergamo, luglio 2012, p. 3. 


\section{Referências Bibliográficas}

> ANCESCHI, Giovanni. Il campo della grafica italiana, "Rassegna" n.6, C.I.P.I.A., Bologna, 1981.

> MUTARELLI, Donato (org.), Le parole della pubblicità, dizionario della lingua pubblicitaria, Pola Libri, Milano 1981.

> BAUDRILLARD, Jean, La società dei consumi, Bologna, II Mulino, 1976.

BENJAMIN, Walter, Parigi capitale del XX secolo, Torino, Einaudi, 1986.

BONSIEPE, Gui, Teoria e pratica del disegno industriale, Milano, Feltrinelli, 1975.

BUCCHETTI, Valeria, La messa in scena del prodotto, FrancoAngeli editore, Milano 2004.

> DORFLES, Gillo, Introduzione al disegno industriale, P.B.E. Torino, 1972.

> ENCICLOPEDIA Europea Garzanti, editrice Carzanti Libri.

> PANSERA, A. (et al), Visual Design; cinquant'anni di produzione in Italia, Idealibri, Milano, 1984.

> MALDONADO , Tòmas, La speranza progettuale, Torino, Einaudi, 1970.

> SEMPRINI, Andrea, Marche e mondi possibili, FrancoAngeli, Milano 1993.

> TERENZI, Benedetta (org.) Dal protodesign al design. La qualità dell'oggetto tra passato e presente guardando al futuro; atti del convegno Finitura at Oltre 2007, Fiera di Bergamo, Sestante Edizioni, Bergamo 2007.

> TERENZI, Benedetta, Il progetto a due dimensioni. Riflessioni propedeutiche al design grafico con esperienze didattiche, edizioni Valle Imagna, Stampa Grafica Monti, Bergamo, luglio 2012.

> TERENZI, Benedetta, Progetto e design nel settore dell'occhialeria, in "I'0ttico", Diffusione Scientifica s.r.l., Sesto Fiorentino, maggio-agosto 2011.

> UBERTAZZI, Alessandro (et al), Classificazione di componenti per il coordinamento dell'immagine aziendale, dispensa del DA, Centro per il Disegno Ambientale, Milano, febbraio 1972.

> UBERTAZZI, Alessandro, Manuali Upim, 1967-1969. Un progetto di grafica sistematica, in "Rassegna" n. 6 (Il campo della grafica italiana), C.I.P.I.A., Bologna, aprile 1981.

> UBERTAZZI, Alessandro, Dalle due alle tre dimensioni, premessa in Dalle due alle tre dimensioni. Riflessioni propedeutiche ...... di Benedetta Terenzi, Edizioni Vallelmagna, luglio 2012.

> UBERTAZZI, Alessandro (et al), Note per definire il concetto di immagine aziendale coordinata, dispensa del DA, Centro per il Disegno Ambientale, Milano, febbraio 1972. 
Aspectos estratégicos da marca para

a construção da imagem empresarial

Benedetta Terenzi, formada em arquitetura pela Universidade de Florença (Itália), tem doutorado em Design Industrial, Ambiente e História, é pesquisadora do Departamento de Tecnologias da Arquitetura e Design (TAD) e docente no curso de graduação em Cultura e Projetação da Moda da Universidade de Florença.

dppg.ceart@udesc.br 